\title{
MULTIMEDIA TEXTBOOK: GERMAN FOR MECHANICAL ENGINEERING
}

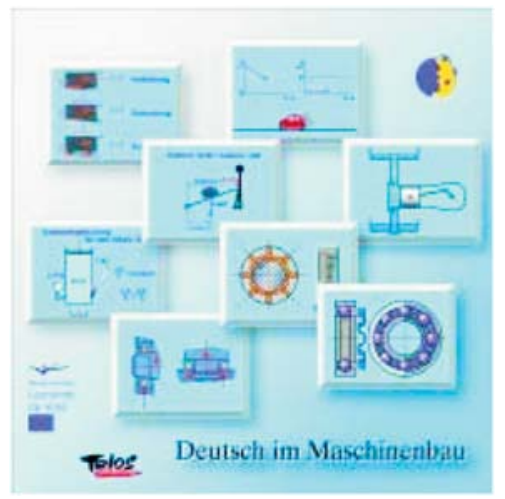

In our presentation we would like to inform about the international project DEUMA called "German for Mechanical Engineering". This project was supported by the European Union as part of LEONARDO DA VINCI II program in which 11 partners from 5 countries participated. The aim of the project was to create a multimedia textbook of technical German language that would be designed especially for students of Faculties of Mechanical Engineering as well as for other students of German language with the focus on its use in the field of professional engineering. DEUMA teaching materials are modern multimedia language tools helping to improve professional German language knowledge in the field of mechanical engineering for Czech, Slovak and French students, teachers and practitioners in the field. The Internet and CD ROM versions enable both self-study and "blended learning" as a combination of classroom teaching and e-learning.

Keywords: Mechanical engineering, multimedia textbook, technical German language, elearning, blended learning, Internet and CD ROM versions.

\section{Introduction}

Computers, Internet, e-mail, multimedia, e-learning, blended learning etc. Those are the terms which definitely belong to our common life today. The times, when Johannes Gutenberg (1438) invented book-printing and the mankind was looking forward to the end of the era when the access to the written word was dedicated only to the small amount of people who were able to get in touch with these documents, were over. If we observe this situation from the present point of view we can say that J. Gutenberg made a revolution in the field of information technology. But who will recall those times when today we are the witnesses of the fact that majority of people who were just recently great enemies of modern technologies reach for computers which make their work easier and, at the same time, more effective. The situation in the production of textbooks for foreign language learning is similar.

Classical, printed textbooks for foreign language learning are gradually supplemented by multimedia courses on DVD, $\mathrm{CD}$, or by their shortened versions on the Internet. In our contribution we would like to inform you about the first multimedia textbook of German language for the needs of students and professionals working in the field of mechanical engineering which appeared in our book market by the end of 2005. From the present point of view we are not talking about a new release in the right sense of the word but about a release verified by several years of practice. It is known to all involved German teachers, mainly to those teach- ing at technical universities, that textbooks for professional teaching of German language are mostly outdated, their choice is very limited, in other words, there is just a small amount of convenient textbooks which comply with the criteria laid on the modern textbook of German language for professionals. Those were the impulses and at the same time the reasons why we decided to participate in the international project in the framework of the program EU Leonardo da Vinci II. The Project was approved by the European commission in 2001 bearing the name Deutsch im Maschinenbau (DEUMA) with allocated number CZ/01/B/F/LA-134057 and its implementation was carried out in the period from 1 November 2001 to 31 October 2004. 11 various organisations from 5 different countries were engaged in the Project, 5 partners were from the European Union.

To the partner organisations that were directly involved in the preparation, development and didactic, methodical and professional adaptation of the textbook belonged:

1. Brno University of Technology - Faculty of Mechanical Engineering

2. VŠB - Technical University of Ostrava

3. Chambre de Commerce et d'Industrie du Jura, France

4. The University of Zilina - Department of Foreign Languages, now Institute of Foreign Languages

Those responsible for language and professional-didactic consultancy were:

\footnotetext{
* Anna Tomankova, Sona Gallova

Institute of Foreign Languages, University of Zilina, Slovakia, E-mail: anna.tomankova@ucj.uniza.sk
} 
Goethe-Institut Inter Nationes Praha, Technische Universitat Wien a Universitat Tubingen, where the software with the title Telos Language Partner Pro 4.00 was produced. This software became the basis for the multimedia processing of the textbook DEUMA Those whose main task was the practical evaluation and testing of processed thematic areas and their modules in teaching practice were: S.A. ROBERT BOSCH, (France), SEM Drasov Siemens Electric Machines, Ltd. and TOS Kurim, a. s. All partner institutions that participated in this project as the authors of the textbook also contributed to the validation and testing along with their students.

\section{The project aimed to:}

a) create a multimedia textbook of specialized German language for the professional area of mechanical engineering and thus fill in the gap in the book market with multimedia textbooks of German professional language;

b) combine classical learning of German language with new technologies, support learners' activities in pursuance of individual studies (CD-ROM and web) with interconnection to Tele Tutoring via the Internet;

c) broaden, deepen and strengthen language skills of Czech, French and Slovak learners who use this multimedia textbook with the aim to improve their flexibility and versatility in the European labour market;

d) choose more widely designed topics that can be used effectively to support learning of professional German also at other faculties, other types of schools and educational facilities or at various professional language courses.

\section{Structure of textbook}

The textbook contains ten topics focused on the issues of mechanical engineering in the broader professional context. It can be found in two versions - 4 pieces of CDs and in a shortened form as a web version which can be found on http://www.uni-tuebingen.de/ael/deuma/deuma_overview.htm. The main topics that we chose after extensive discussions with experts are : mathematics, physics, materials, connecting elements, parts of machines - bearings, parts of machines-gear units, parts of machines-pistons and cylinders, apparatuses, devices, and tools, two final topics represent technical dialogues. The first final topic is dedicated to telephone conversations, making contacts, discussions about production problems, finding solutions to problems, management programs, construction of machines etc. The second final topic deals with discussions about projects, missing technical documentation, product development, prototypes etc.

Each topic consists of a greater amount of modules and each module develops the main theme. As an example we introduce the topic Mathematik. It consists of 7 modules: 1 . Numeric fields; 2. Counting with natural numbers; 3. Equations; 4. Basic concepts from geometry; 5. Triangle, rectangle, circle; 6. Geometric solids; 7. Pyramid, cylinder, cone, sphere.

Each module contains:

- input text with video,
- exercises focused on listening and reading comprehension of the text,

- lexical exercises practising professional vocabulary,

- grammar exercises taking into account morphological and syntactic phenomena encountered in the text,

- description of communicative approaches used in the module with the practical use of grammar and structures which students have to master in order to communicate correctly.

The input text or input dialogue is designed to introduce students to the professional problems of carefully sought and selected current professional topics. Videos of each lesson are visual and sound representation of the professional text, or of the dialogue. It appears on the monitor simultaneously in a written form on the right side of the animation. When working with the text we can use all the options which the multimedia processing offers us. We can listen to the text with or without visual support, we can record and listen to ourselves, we can delete the text and record our reproduction, we can act as a partner in a dialogue, in case of not understanding the text we can click on the translation etc. The text is followed by a number of exercises focused on all four language skills - reading, writing, listening and speaking. For navigation reasons the structure is uniformed, clear and we must adhere it in particular topics and modules. This uniformity of processing creates advantage for the learner but disadvantage for the authors of the textbook who are to some extent forced to follow up the pre-programmed templates, types of exercises and the overall structure of all modules. Regarding the choice of exercises, we decided to use mainly these types of exercises:

to practise comprehension of a heard and read text:

- choosing the correct sequence of particular parts of the text (with sound),

- linking the parts of sentences (with or without sound),

- deciding correct - incorrect (true - false) (with or without sound),

- multiple-choice exercises (with or without sound),

- drag \& drop exercises (with or without sound).

to practise vocabulary:

in the beginning of each section which is dedicated to practise vocabulary, there is a list of vocabulary that contains unknown words from the input text. The words are not arranged in alphabetical order but in the order they appear in the text and most of the time also in short passages from the text. This section provides many options how to practise given vocabulary. There are exercises of the type: matching the terms with definitions, drag and drop exercises with moving objects, exercises with gaps for filling in special terms, formation of antonyms, compound words, formation of new words with the help of prefixes and suffixes, superior and inferior terms etc.

to practise grammar:

in this section those grammar phenomena are taken into account and practised with which students have the biggest difficulties. For example: articles, prepositions, comparison of adjectives, nouns, irregular conjugation of verbs, passive voice, attribute, word order 
in the main and subordinate clauses, usage of infinitive with "zu", infinitive constructions etc.

\section{to practise communicative activities:}

the exercises in this section provide students with necessary instructions which language means they should use in order to be able to express their ideas on given topics aptly and promptly. In our textbook the multimedia teaching templates are accessible either in the learning system (Lernmodus) or in the processing system (Bearbeitungsmodus).

Lernmodus is dedicated to individual learning. Bearbeitungsmodus was designed with the aim to enable further processing of the given exercises and tasks by changing a text, picture and also audio material. The program Bearbeitungsmodus allows us to form also internal dictionaries and to connect them with various modules. The last two communicatively oriented topics Technical dialogues form a separate part to practise dialogues. Through these dialogues students learn how to lead business and technical meetings with German speaking partners in a better, quicker and more effective way.

Multimedia software Telos Language Partner includes the following pre-programmed multimedia templates:

- templates for videos,

- templates for text,

- templates for drag and drop exercises,

- templates with gaps for missing words,

- templates for multiple-choice exercises,

- templates for lexical, grammar, professional and other supplementation.

We incorporated already mentioned professional texts into the templates which were processed from the point of view of methodology and didactics very carefully and the texts were transformed into different types of exercises.

To facilitate the work with the multimedia textbook, we provided integrated assistance to students within the program but also the printed user's manual was published in Czech, Slovak and French language.

Additionally, we processed a detailed curriculum how to utilize the textbook at the faculties of mechanical engineering of the participating states. This new integrated didactic - technological concept that mutually connects individual learning with the aid of computer and multimedia textbook also with Tele Tutoring via the Internet, was very successfully tested in terms of pedagogical practice at 7 faculties of mechanical engineering in Slovakia, France and in the Czech Republic as well as at 11 secondary schools specializing in mechanical engineering in the mentioned countries.

Although the textbook is intended to be used first of all in class, we have evidence that students work with the mentioned textbook also outside the class in order to achieve permanent and prime professional language competences.

The results gathered from both planned and random surveys show that our multimedia textbook is useful and helpful to all those who decided to learn from it. DEUMA and its authors received on 26 September 2003 the Award from the European Commission and the Ministry of Education of the Czech Republic - European Language Label 2003.

\section{Place of multimedia textbooks in teaching foreign languages, their advantages and disadvantages}

In the future no school, no school facility no matter how demanding the study will be, will not be able to ignore multimedia textbooks because the whole world, the whole human society is very closely and firmly connected with new information technologies. On the other hand, however, the publishers of classical books and educators who prefer a printed form of textbooks should not be afraid of the fact that multimedia textbooks will replace traditional textbooks and that they will even replace the teacher. It is absolutely clear that the role of a teacher and the form of interaction teacher-student will always change in the scope of teaching. Present-day extensive discussions on the merits of multimedia textbooks, on their efficiency in the foreign language learning rather than using traditional textbooks in a written and printed form, which in the opinion of some teachers encourage the students to converse more, this fact leads us to the conclusion that if we consider a multimedia textbook it is about the communication of human being with the computer. That apparently does not correspond with the current life situations. Objectively, we believe there are still just a few studies dealing with the influence of multimedia language programs on the learner's success. Different types of research and comparative studies show that there is $30-33 \%$ more stimulation to learn when using multimedia activities. On the other hand some other studies indicate either a very small or even no difference in efficiency of foreign language learning between the classical learning activities and those supported by multimedia. However, the objectivity of these comparative studies and research of efficiency is being discussed among experts because there are no generally valid instruments to measure efficiency and accurately defined comparative criteria of success in foreign language learning. It is actually the reason why success in learning and efficiency cannot be objectively measured.

In the context of a rather limited opinion poll carried out on a sample of 154 students we came to the conclusion that all the participants welcomed the use of multimedia programs in foreign language learning. The students believe that their main advantages over the traditional textbooks are: self-activity in learning, they can determine the order of exercises and tasks themselves, choose topics themselves, test themselves and view the evaluation, test results are stored in the computer after they exit the program, multimedia processing offers variety of special functions - translation of texts, of technical terms, instructions for grammar exercises, practising those grammar structures which occur in professional texts, they practise the language within the framework of forum, they advise each other and help each other when solving problems etc. Whatever the conclusions of these discussions are, we, the teachers of foreign languages can only welcome any teaching aid which will make our work more effective. 
Of course, we have to define precisely the target group, i. e., for whom the specific textbook is intended. The situation is different, for example, in courses for adults who are generally less proficient and flexible when using the computer the multimedia textbooks can cause stress and anxiety in students or create psychological barriers. In our university practice we become witnesses of the fact that students got very quickly used to the omnipotent medium - the computer. They even work very willingly with multimedia language programs and they prefer them to other sources of learning. They complete all the tasks which are somehow con- nected with computer or the Internet which are being assigned to them responsibly and in time. That was also the main reason which led us to the decision, in absence of literature, to compile the multimedia textbook instead of a traditional one.

For illustrative purposes we present several examples to illustrate the structure, content and processing of the multimedia textbook DEUTSCH IM MASCHINENBAU - Fig.1.

Content of the book:

\section{Deutsch im Maschinenbau}

Ein Produkt des Leonardo-da-Vinci-Projektes DEUMA

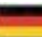

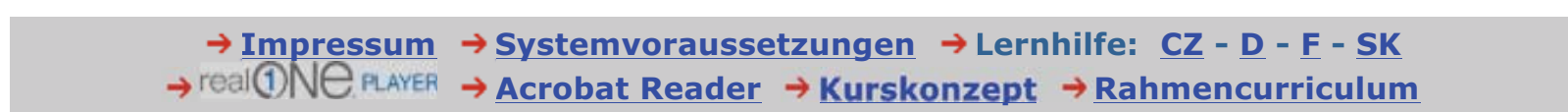
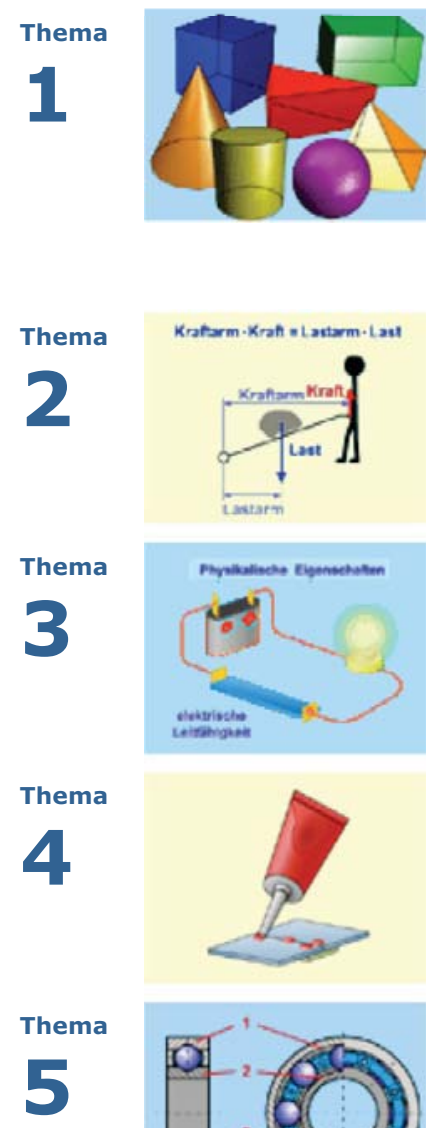

MATHEMATIK

PHYSIK

WERKSTOFFE

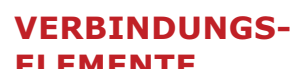

\section{ELEMENTE}

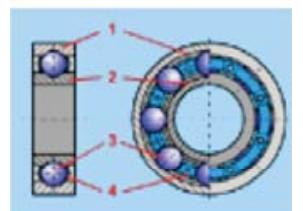

LAGER $\rightarrow$ M1 Zahlenbereiche

$\rightarrow$ M2 Rechnen mit natürlichen Zahlen

$\rightarrow$ M3 Gleichungen

$\rightarrow$ M4 Grundbegriffe der Geometrie

$\rightarrow$ M5 Dreieck, Viereck, Kreis

$\rightarrow$ M6 Körper

$\rightarrow$ M7 Pyramide, Kegel, Zylinder, Kugel

$\rightarrow$ M1 Einheiten

$\rightarrow$ M2 Bewegungen von Körpern

$\rightarrow$ M3 Kreisbewegung und Drehmoment

$\rightarrow$ M4 Reibung

$\rightarrow$ M5 Druck

$\rightarrow$ M1 Werkstoffeinteilung

$\rightarrow$ M2 Werkstoffeigenschaften

$\rightarrow$ M3 Stahlherstellung

M1 Stoffschlüssige Verbindungen

$\rightarrow$ M2 Schrauben und Gewinde

$\rightarrow$ M3 Welle-Nabe-Verbindungen

$\rightarrow$ M4 Dialog zu Verbindungselementen

\footnotetext{
$\rightarrow$ M1 Gleitlager

$\rightarrow$ M2 Walzlager

$\rightarrow$ M3 Lagergestaltung und -berechnung

$\rightarrow$ M4 Lagerherstellung
} 


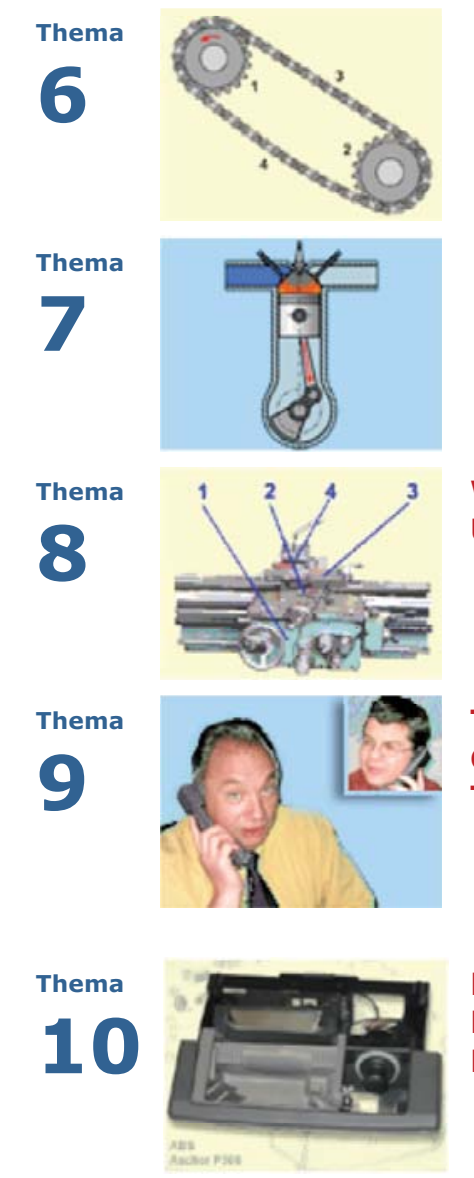

\author{
GETRIEBE $\rightarrow$ M1 Zahnradgetriebe \\ $\rightarrow$ M2 Riementriebe \\ $\rightarrow$ M3 Kettentriebe \\ $\rightarrow$ M4 Getriebewahl
}
WERKZEUGE $\rightarrow$ M1 Werkzeuge
UND GERÄTE $\rightarrow$ M2 Bohr- und Fräsmaschinen
$\rightarrow$ M3 Drehmaschinen
$\rightarrow$ M4 CNC-Werkzeugmaschinen
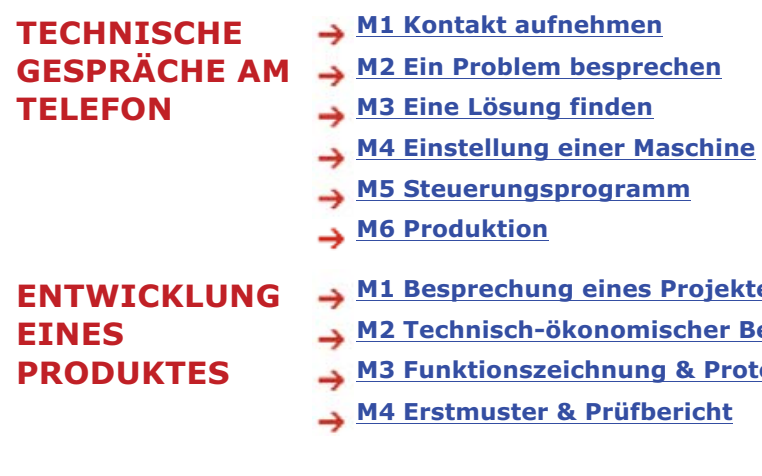
$\rightarrow$ M1 Kolbenmaschinen
$\rightarrow$ M2 Kolbenverdichter
$\rightarrow$ M3 Verbrennungsmotoren
$\rightarrow$ M4 Zweitakt oder Viertakt?

Fig. 1 The structure, content and processing of the multimedia textbook Deutsch im Maschinenbau

Demonstration of a practical guide of how to work with the multimedia textbook DEUTSCH IM MASCHINENBAU

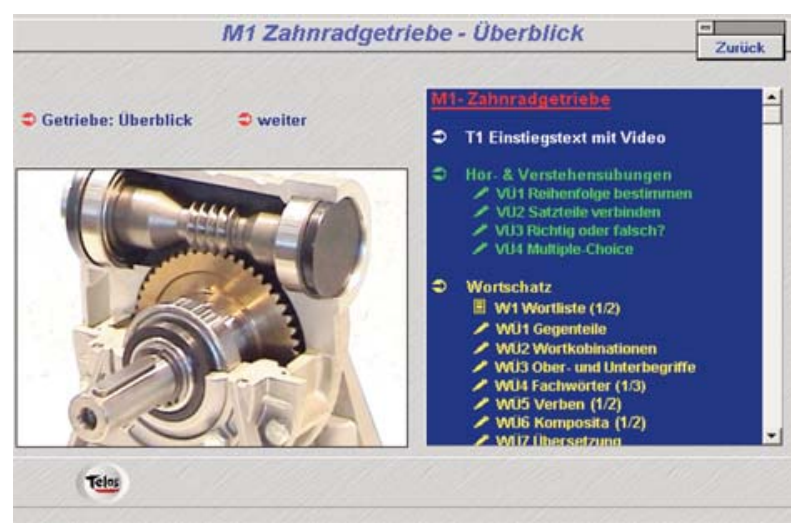

Fig. 2 Gear drive [1]

Start every new activity by going to the outline of topics/Themenuberblick - Fig. 2 and choose one of the modules. From the intro- duction page of the module/Moduluberblick there is an access to the particular parts of the learning module (Lernmodul). In addition, you can find a reference to the link Lernhilfe/help, which will provide you with valuable didactic instructions for each type of task.

With the help of button Telos you can get to the content and any part of the chosen module can be accessed.

\section{Work with video}

First of all you must become familiar with the video in order to understand the content of the video well - Fig. 3.

Watch and listen to the video, look up the unknown words and practise chosen grammar structures.

\section{Tasks}

$1^{\text {st }}$ step: listening to the dialogue

- First, watch the video without the support of the written text Fig. 4. Delete the text by clicking on delete button/LoschButton . Listen to the text and try to understand as much as possible.

- You can control the video with the help of buttons on the control sound panel below the window with video. 


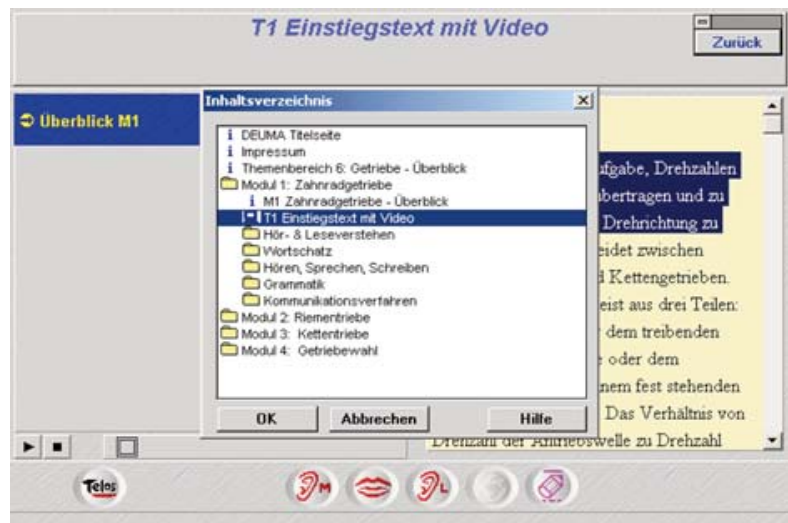

Fig. 3 Content [1]

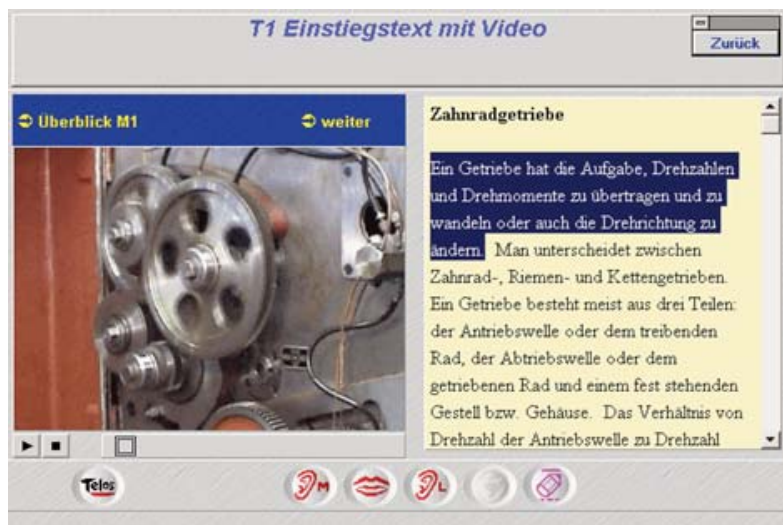

Fig. 4 Text and video [1]

- play the video

stop the video

II pause

move the video forward or backward.

$2^{\text {nd }}$ step:

- Refresh the text once again and watch the video. Shift the button with eye on grey field and the text is displayed again.

- Look up the unknown words in the appropriate dictionary.

- Open the notepad (by clicking on Notepad in menu Extras) and write down new words or word collocations.

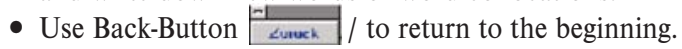

\section{Work with dialogue}

Dialogue exercises are led by participants of the dialogue to drill their roles and expression in the flexible combination of listening, reading and speaking.

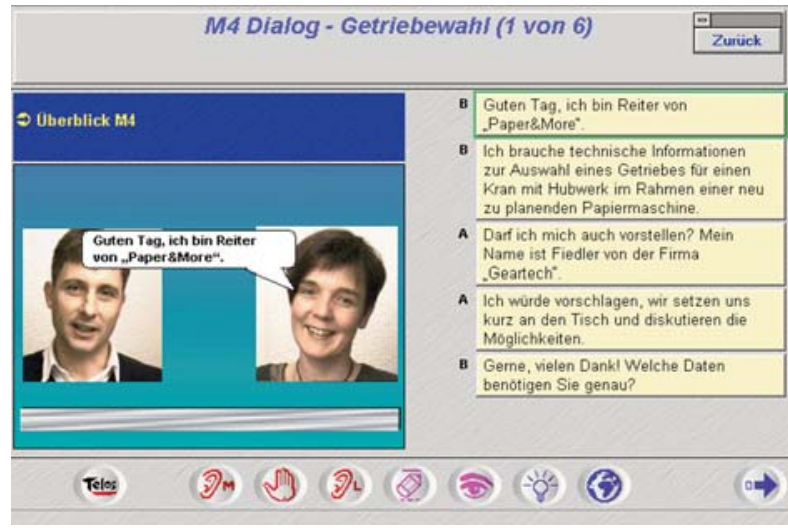

Fig. 5 Dialogue [1]

Tasks

$1^{\text {st }}$ step: listening to the dialogue

- Delete the text of the dialogue (by shifting the button for delete (8) to a situation picture), then listen to the dialogue or its parts once or more times (shift the reproduction button to a situation picture or to some text fields) and try to understand as much as possible.

- Refresh the text again (by shifting button with eye 5 to a situation picture). Listen to the dialogue again and use the written text as the aid for understanding - Fig. 5.

\section{$2^{\text {nd }}$ step: looking up}

- Look the unknown words up in the appropriate dictionary.

- Open the notepad (by clicking on Notepad in the menu Extras) and write down the new words or word collocations.

\section{$3^{\text {rd }}$ step: listening and recording}

- Repeat the parts of the text and record yourself (shift the button with recording to $\Leftrightarrow$ the text).

- Compare your recording with the model (alternately shift the button with model (2) and the button of a learner (3) over a text field).

If you are not satisfied with your performance repeat the recording.

\section{$4^{\text {th }}$ step: writing}

- Delete the text of the dialogue (shift the button to a situation picture). Listen to a part of the dialogue and write it down as a dictation into the appropriate field.

- Compare your text with the original (shift the button for solutions $(-i ;$ to the text).

- Delete parts of the dialogues or the whole dialogue (shift the delete button to the text field or to any head of the speaker in the picture) and try to write down the text by heart without repeated listening.

\section{5th step: role game}

- Choose one role in the dialogue (shift the recording button $\Leftrightarrow$ to selected head of the person on the situation picture) and record yourself. 
- Listen to your recording (shift the reproduction button of the learner ( $)$ to the situation picture).

- Compare your recording with the model.

- Repeat the dialogues until you are satisfied with your performance.

- Delete the text of the dialogue and repeat it again.

\section{Conclusion}

We are convinced that our multimedia course will be very useful for those who will use it to improve their language and communication competencies in the field of mechanical engineering. We are grateful to the European Union for the fact that variety of its programs are oriented on modernisation and increasing the efficiency of learning/teaching foreign languages and in our case on the modernisation of learning/teaching the professional German language. We must be aware of the fact that modern foreign language teaching requires also quality, creative and committed teach- ers, pleasant atmosphere in the classroom and many other additional activities [2]. Thorough preparation for the modern knowledge society requires, on the one hand broad knowledge of our students in the field of foreign languages and on the other hand, from our side, it means from the side of foreign language teachers, introduction and utilisation of new modern didactic methods which support the autonomy of students in learning and they place them as active members of the learning process into the centre of foreign language education. The use of our multimedia textbook for learning/teaching German professional language contributes to this fact. We must not forget that even the most perfect technique, multimedia programs and textbooks are not able to substitute either the teacher, or the teaching process. The role of the teacher is changing when multimedia language courses are being used - teachers become more navigators, presenters or tutors of their students. We wish us and also our potential students who choose to learn professional German for mechanical engineering from our multimedia textbook a lot of success, joy and enthusiasm in their studies.

\section{References}

[1] Telos Language Partner - Benutzerhandbuch und Materialien zum Projekt DEUMA.

[2] KRALOVA, Z.: Vyucovanie cudzojazycnej vyslovnosti [Teaching Foreign Language Pronunciation], Cudzie jazyky a kultúry v modernej skole (Foreign Languages and Cultures at Modern School), Brno : Masarykova univerzita, 2009, pp. 183-197, ISBN 978-80210-4974-1 